\title{
GAMBARAN, KARAKTERISTIK PENGGUNA DAN PERSEPSI NELAYAN TERHADAP KEMANFAATAN SISTEM APLIKASI NELAYAN PINTAR (SINP) DI PELABUHAN PERIKANAN INDONESIA
}

\section{Overview, Characteristics of Users and Fisher Perception for Usefulness of Smart Fisher Application System (SINP) in Indonesia Fishing Port}

\author{
*Umi Muawanah¹, Penny Dyah Kusumaningrum², Hadhi Nugroho² dan Donald Daniel² \\ 'Balai Besar Riset Sosial Ekonomi Kelautan dan Perikanan \\ Gedung Balitbang KP I Lt. 4 \\ Jalan Pasir Putih Nomor 1 Ancol Timur, Jakarta Utara, Indonesia \\ Telp: (021) 64711583 Fax: 64700924 \\ ${ }^{2}$ Pusat Penelitian dan Pengembangan Sumber Daya Pesisir dan Non-Hayati \\ Diterima tanggal: 20 Pebruari 2017 Diterima setelah perbaikan: 9 Mei 2017 \\ Disetujui terbit: 6 Juni 2017 \\ *email: umi.muawanah@gmail.com
}

\begin{abstract}
ABSTRAK
Sistem Informasi Nelayan Pintar (SINP) adalah sebuah aplikasi android yang menampikan informasi-informasi penting untuk para nelayan dalam melaut. Informasi SINP terdiri dari informasi daerah penangkapan ikan, cuaca, harga ikan, dan dinamika laut. Makalah ini bertujuan mengulas beberapa hal tentang sistem Nelayan Pintar di Indonesia yaitu: (1) deskripsi sistem kerja sisten SINP, (2) gambaran demografi nelayan calon pengguna NISP dan (3) persepsi nelayan terhadap kemanfaatan beberapa informasi yang ditampilkan dalam perangkat SIN. Penelitian ini menemukan bahwa menurut nelayan, informasi yang dirasa sangat bermanfaat adalah peta DPI dan prakiraan cuaca sebelum melaut. Prakiraan cuaca ini penting untuk keselamatan nelayan. Dalam pertanyaan lanjutan tentang manfaat informasi Daerah Penangkapan Ikan ini, responden 84,1 \% menyatakan bawah informasi atau peta DPI meningkatkan hasil tangkapan dibanding tidak membaca peta DPI. Peta DPI dapat diperoleh oleh nelayan di setiap pelabuhan perikanan seluruh Indonesia. Para nelayan juga merasa bahwa sistem SINP cukup mudah untuk dioperasikan.
\end{abstract}

Kata Kunci: SINP, persepsi, daerah penangkapan ikan, pelabuhan perikanan, pemilik kapal

\section{ABSTRACT}

Smart Fishers Information system (called SINP in Bahasa) is an android based application displaying important information for fishers to go fishing. The system has information on fishing ground location and coordinates, weather, fish price, and ocean dynamics. This paper elaborates the SINP system, some demographic characteristics of its users and fisher's perception on SINP. According to the users, the most important information is the fishing ground location and their coordinates. Almost 84.1 $\%$ respondents claim that the fishing ground location does help increase the catch. The map of fishing ground can be obtained from the office of provincial or district fishing port. The fishers feel that the SINP is user friendly and easy to operates.

Keywords: SINP, perception, fishing ground, fishing port, ship owner

\section{PENDAHULUAN}

Informasi dan teknologi merupakan komponen penting dalam keberhasilan ekonomi untuk berbagai sektor seperti pertanian dan perikanan di daerah-daerah terpencil dan daerah pesisir (Omar et al., 2011). Pada umumnya di Indonesia, pola penangkapan ikan oleh nelayan, terutama dalam skala kecil adalah bersifat tradisional. Usaha kegiatan penangkapan ikan merupakan warisan turun-temurun dengan memperhatikan kondisi lingkungan sekitar, seperti pola bintang, awan, dan gelombang. Usaha penangkapan ikan oleh nelayan tersebut menjadi usaha yang sifatnya berburu ikan. Kurangnya informasi mengenai daerah potensi penangkapan ikan mengakibatkan lokasi yang diperkirakan banyak ikannya oleh nelayan terkadang ternyata 
sangat sedikit atau tidak ada ikannya sama sekali. Karena itu, hasil tangkapan menjadi tidak maksimal, kurang efisien, serta biaya operasional menjadi lebih besar. Setelah ikan diperoleh, nelayan pada umumnya juga tidak memiliki pilihan dalam memasarkan atau menjual ikan hasil tangkapannya karena nelayan juga kurang memperoleh informasi mengenai harga ikan terkini di pasaran. (Sumber : komunikasi pribadi dengan Adhi Candra, Direktur Kenelayanan, Direktorat Jenderal Perikanan Tangkap (DJPT), Februari 2015).

Informasi penting yang dibutuhkan nelayan di Indonesia antara lain adalah informasi daerah penangkapan ikan, informasi cuaca, informasi harga ikan, informasi dinamika laut, dan sebagainya. Informasi-informasi tersebut selama ini sulit diperoleh dalam satu sistem. Misalnya informasi peta prakiraan daerah penangkapan ikan (PPDPI) diperoleh dari papan pengumuman pelabuhan setempat atau website Balai Penelitian dan Observasi Laut (BPOL). Informasi prakiraan cuaca diperoleh dari Badan Meteorologi, Klimatologi, dan Geofisika (BMKG). Informasi kesuburan perairan diperoleh dari Infrastructure Development of Space Oceanography (INDESO) - Kementerian Kelautan dan Perikanan (KKP). Informasi harga ikan diperoleh di Pusat Informasi Pelabuhan Perikanan (PIPP) - KKP. Beberapa informasi disampaikan kepada nelayan yang berada di tengah laut dengan menggunakan radio komunikasi high frequency. Namun, kelemahan komunikasi dengan radio adalah informasi yang terdistribusikan juga terbatas. Oleh karena itu, informasi-informasi yang berasal dari berbagai institusi tersebut disatukan atau diintegrasikan dalam satu sistem yang berbasis Operating Sistem (OS), sehingga memudahkan nelayan mengakses dalam satu perangkat komunikasi. Sistem yang dibangun oleh Pusat Pengkajian dan Perekayasaan Teknologi Kelautan dan Perikanan (P3TKP) - Badan Peneitian dan Pengembangan Kelautan dan Perikanan (Balitbang KP) pada tahun 2015 dinamakan Sistem Informasi Nelayan Pintar (SINP). Dengan konsep SINP, sebelum melaut nelayan dapat mengakses berbagai informasi terkini tentang daerah penangkapan dan kondisi cuaca di mana pun mereka berada melalui satu aplikasi pada perangkat gadget yang mereka miliki. Setelah selesai menangkap ikan, nelayan juga dapat mengakses informasi terkini tentang harga ikan sehingga mempunyai banyak pilihan untuk menjual jenis ikan dan tempat pelelangan dengan harga ikan yang baik.
Kajian pendahulu tentang kemanfaatan sistem informasi untuk nelayan sangat minim atau mungkin belum ada. Omar et al. (2011) mengulas tentang desain dan kemanfaataan sistem informasi dan teknologi (Information and Communication Technology) ICT dan kemanfaatan untuk sektor industri perikanan di Malaysia. Penelitian ini mengkaji peran dari ICT tersebut dalam meningkatkan pembangunan sektor industri perikanan di Malaysia. Dalam sistem SINP ini, sistem informasi disajikan kepada nelayan skala kecil dengan tujuan untuk meningkatkan ekonomi perikanan. Peningkatan ekonomi perikanan dapat berbentuk: bertambahnya hasil tangkapan, berkurangnya biaya melaut dan atau informasi harga ikan yang membantu para nelayan.

Kajian persepsi lain yang melibatkan persepsi nelayan terhadap semua tata kelola atau kelembagaan atau sebuah program di bidang perikanan cukup banyak (Pérez-Sánchez \& Muir, 2003; Pet-Soede et al., 1999; Pomeroy \& Douvere, 2008; McClanahan et al., 2005.). Zamroni dan Yamao (2011) mengkaji persepsi nelayan terhadap program penamanan rumput laut di Sulawesi. Kajian ini menemukan bahwa perlahan-lahan, penamanamn rumput laut sebagai salah satu alternatif mata pencaharian untuk masyarakat nelayan dan pesisir dapat menggantikan usaha di sektor perikanan. Zamroni juga menemukan bahwa masyarakat pesisir di Sulawesi Selatan masih mempunyai permasalahan di pemasaran dan channeling untuk produk rumput laut.

Kajian-kajian tentang persepsi pengguna atau pemangku kepentingan kadang digunakan untuk menjembatani dan melengkapi kajian ilmiah dalam tujuan pengelolaan sumber daya. Dalam pengelolaan perikanan, kadang ilmuwan perikanan dan pengambil kebutuhan perlu memasukkan pengetahuan nelayan (atau disebut fisher's knowledge) ke dalam tata kelola atau kelembagaan manajemen sumber daya perikanan. Hal ini mampu meredam konflik antara nelayan dan pengelola serta keterlibatan pengguna secara aktif mampu meningkatkan efektivitas kelembagaan pengelolaan tersebut (Muawanah et al., 2013 dan Pomeroy et al., 2007). Muawanah dan Hidayat (2016) meneliti tentang persepsi nelayan terhadap program Coral ReefManagement Project (COREMAP) di beberapa wilayah di Indonesia Timur. Dari kajian ditemukan bahwa persepsi nelayan dengan menggunakan teknik survei sosial mendukung data hasil monitoring tim COREMAP dalam survei ekologi di 
lapangan dan di kawasan Marine Protected Area di wilayah-wilayah COREMAP.

Makalah ini bertujuan mengulas beberapa hal tentang sistem Nelayan Pintar di Indonesia yaitu:1) deskripsi sistem kerja sisten SINP, 2) gambaran demografi nelayan calon pengguna NISP dan 3) persepsi nelayan terhadap kemanfaatan beberapa informasi yang ditampilkan dalam perangkat SINP. Data-data tersebut didapat melalui survei kepada para nelayan dan Departemen Kelautan dan Perikanan (DKP) daerah di lokasi-lokasi pelabuhan perikanan seluruh Indonesia. Rekomendasi hasil kajian ini akan menjadi masukan dalam pengembangan SINP oleh Balitbang Kelautan dan Perikanan untuk perbaikan sistemnya dan Direktorat Jenderal Perikanan Tangkap untuk aspek kelayakan dan kemudahan operasinya untuk para nelayan.

\section{METODOLOGI}

\section{Lokasi dan Waktu Penelitian}

Penelitian dilakukan di 27 pelabuhan perikanan di Indonesia. Penelitian dilaksanakan pada bulan September-Desember 2015. Namanama pelabuhan dan jumlah responden tertera pada Tabel 1.

Tabel 1. Nama-nama Pelabuhan Perikanan Lokasi Survei dan Jumlah Responden.

Table 1. The Names of Fishery Port Survey Location and Number of Respondents.

\begin{tabular}{|c|c|c|c|}
\hline No & $\begin{array}{l}\text { Nama Pelabuhan/ } \\
\text { Names of Fish Port }\end{array}$ & $\begin{array}{c}\text { Kota/ Kab dan Provinsi/ } \\
\text { Cities/ Regency and Provinces }\end{array}$ & $\begin{array}{l}\text { Jumlah Responden/ } \\
\text { Totsl Respondent }\end{array}$ \\
\hline 1 & PPP Lampulo & Kota Banda Aceh, Aceh & 23 \\
\hline 2 & PPI Labuhan Haji & Kab. Aceh Selatan, Aceh & 26 \\
\hline 3 & PPN Sibolga & Kota Sibolga, Sumatra Utara & 27 \\
\hline 4 & PPN Sungai Liat & Kab. Bangka, Bangka-Belitung & 28 \\
\hline 5 & PPP Kota Agung & Kab. Tanggamus, Lampung & 21 \\
\hline 6 & PPP Lempasing & Kota Bandar Lampung, Lampung & 33 \\
\hline 7 & PPN Karangantu & Kota Serang, Banten & 21 \\
\hline 8 & PPS Nizam Zachman & Kota Jakarta Utara, DKI Jakarta & 10 \\
\hline 9 & PPN Palabuhan Ratu & Kab. Sukabumi, Jawa Barat & 24 \\
\hline 10 & PPN Kejawanan & Kota Cirebon, Jawa Barat & 27 \\
\hline 11 & PPS Cilacap & Kab. Cilacap, Jawa Tengah & 22 \\
\hline 12 & PPP Tegalsari & Kota Tegal, Jawa Tengah & 9 \\
\hline 13 & PPN Pekalongan & Kota Pekalongan, Jawa Tengah & 21 \\
\hline 14 & PPN Brondong & Kab. Lamongan, Jawa Timur & 29 \\
\hline 15 & PPN Prigi & Kab. Trenggalek, Jawa Timur & 23 \\
\hline 16 & PPN Pengambengan & Kab. Jembrana, Bali & 18 \\
\hline 17 & PPN Pemangkat & Kab. Sambas, Kalimantan Barat & 21 \\
\hline 18 & PPS Bitung & Kota Bitung, Sulawesi Utara & 15 \\
\hline 19 & PPI Tumumpa & Kota Manado, Sulawesi Utara & 19 \\
\hline 20 & PPN Kwandang & Kab. Gorontalo Utara, Gorontalo & 23 \\
\hline 21 & PPI Tilamuta & Kab. Boalemo, Gorontalo & 17 \\
\hline 22 & PP Donggala & Kab. Donggala, Sulawesi Tengah & 20 \\
\hline 23 & PPS Kendari & Kota Kendari, Sulawesi Tenggara & 27 \\
\hline 24 & PPN Ternate & Kota Ternate, Maluku Utara & 13 \\
\hline 25 & PPP Bacan & Kab. Halmahera Selatan, Maluku Utara & 10 \\
\hline 26 & PPN Ambon & Kota Ambon, Maluku & 27 \\
\hline 27 & PPP Klademak & Kota Sorong, Papua Barat & 28 \\
\hline \multicolumn{3}{|c|}{ Total Responden/ Total Respondent } & 582 \\
\hline
\end{tabular}




\section{Jenis dan Sumber Data}

Data primer yang dikumpulkan meliputi informasi tentang kebiasaan atau pola tingkah laku nelayan sebelum melaut meliputi melihat prakiraan cuaca, prakiraan harga ikan, prakiraan tempat fishing ground dan kemudahan aplikasi SINP untuk dioperasikan. Sedangkan data primer responden nelayan meliputi umur, pendidikan, alat tangkap, ukuran kapalnya dan jabatan nelayan dalam kapal tersebut. Persepsi nelayan diperoleh dari pertanyaan-pertanyaan yang diajukan ke responden mengenai pendapat reponden terhadap SINP dan kemanfaatannya.

\section{Metode Pengumpulan Data}

Survei tentang kemanfaatan SINP dilakukan dengan mensurvei para responden pada waktu dilakukan sosialisasi SINP di 27 pelabuhan perikanan seluruh Indonesia dengan menjaring 582 responden. Sebelum melakukan sosialisasi program SINP, peralatan kuesioner dibuat untuk menganalisa kemanfaatan dari sistem SINP ini menurut para nelayan (responden). Responden terdiri dari para pemilik kapal dan kapten kapal.

\section{Analisis Data}

Data dianalisa dengan menggunakan metode statistika yang sederhana untuk menghasilkan deskripsi statistika dan persentase. Data-data hasil survei ditabulasi dengan Microsoft Excel dan untuk kemudahan ditampilkan dalam bentuk grafik untuk pembahasan.

\section{HASIL DAN PEMBAHASAN}

\section{Sistem Operasi Android}

Sistem Informasi Nelayan Pintar pada tahun 2015 dibangun pada aplikasi berbasis sistem operasi android. Pemilihan sistem operasi android ini didasarkan pada beberapa kelebihan yang dimilikinya. Kelebihan pertama adalah sistem operasi android bersifat user friendly. Artinya, sistem operasi android sangat mudah dioperasikan, bahkan orang yang belum pernah menggunakan android akan mampu mengoperasikannya dalam waktu yang singkat.

Dengan demikian, nelayan tidak akan kesulitan dalam mengoperasikan SINP. Kelebihan kedua adalah sistem operasi android bersifat open source. Android dibangun di atas kernel Linux, sehingga siapa pun dapat mengembangkan dan memodifikasi Android tanpa harus membayar. Karena itu, P3TKP dapat secara bebas membangun dan mengembangkan SINP berbasis android. Kelebihan ketiga adalah sistem operasi android banyak digunakan oleh pengguna smartphone pada berbagai kalangan masyarakat. Hal ini menyebabkan smartphone berbasis android sangat mudah ditemukan di pasaran dengan harga yang relatif terjangkau. Dengan demikian, nelayan tidak akan kesulitan dalam memperoleh perangkat keras smartphone berbasis android.

\section{Desain Sistem Informasi Nelayan Pintar (SINP)}

Data dan informasi yang terdapat di dalam sistem informasi nelayan pintar adalah sebagai berikut:

- Informasi peta prakiraan daerah penangkapan ikan (PPDPI)

- Data diambil dari Balai Penelitian dan Observasi Laut (BPOL) di Perancak, Jembrana, Bali. Data yang ditampilkan di aplikasi android adalah data PPDPI dalam radius 100 mil dari lokasi dimana perangkat saat itu berada.

- Informasi prakiraan cuaca

- Data diambil dari situs web BMKG untuk prakiraan cuaca wilayah perairan.

- Informasi kesuburan perairan

- Data diambil dari INDESO

- Informasi harga ikan

Data diambil dari Pusat Informasi Pelabuhan Perikanan, Direktorat Pelabuhan Perikanan, Direktorat Jenderal Perikanan Tangkap, Kementerian Kelautan dan Perikanan.

Pengambilan dataPPDPI, kesuburan perairan, dan harga ikan dilakukan dengan menggunakan web service. Sedangkan pengambilan data prakiraan cuaca perairan langsung dari situs web BMKG. Data yang diambil melalui web service diambil dan disimpan secara periodik ke dalam database. Data yang ditampilkan di android diolah dan diproses melaui web service. Proses integrasi informasiinformasi tersebut ke dalam aplikasi android dapat dilihat pada Gambar 1. 


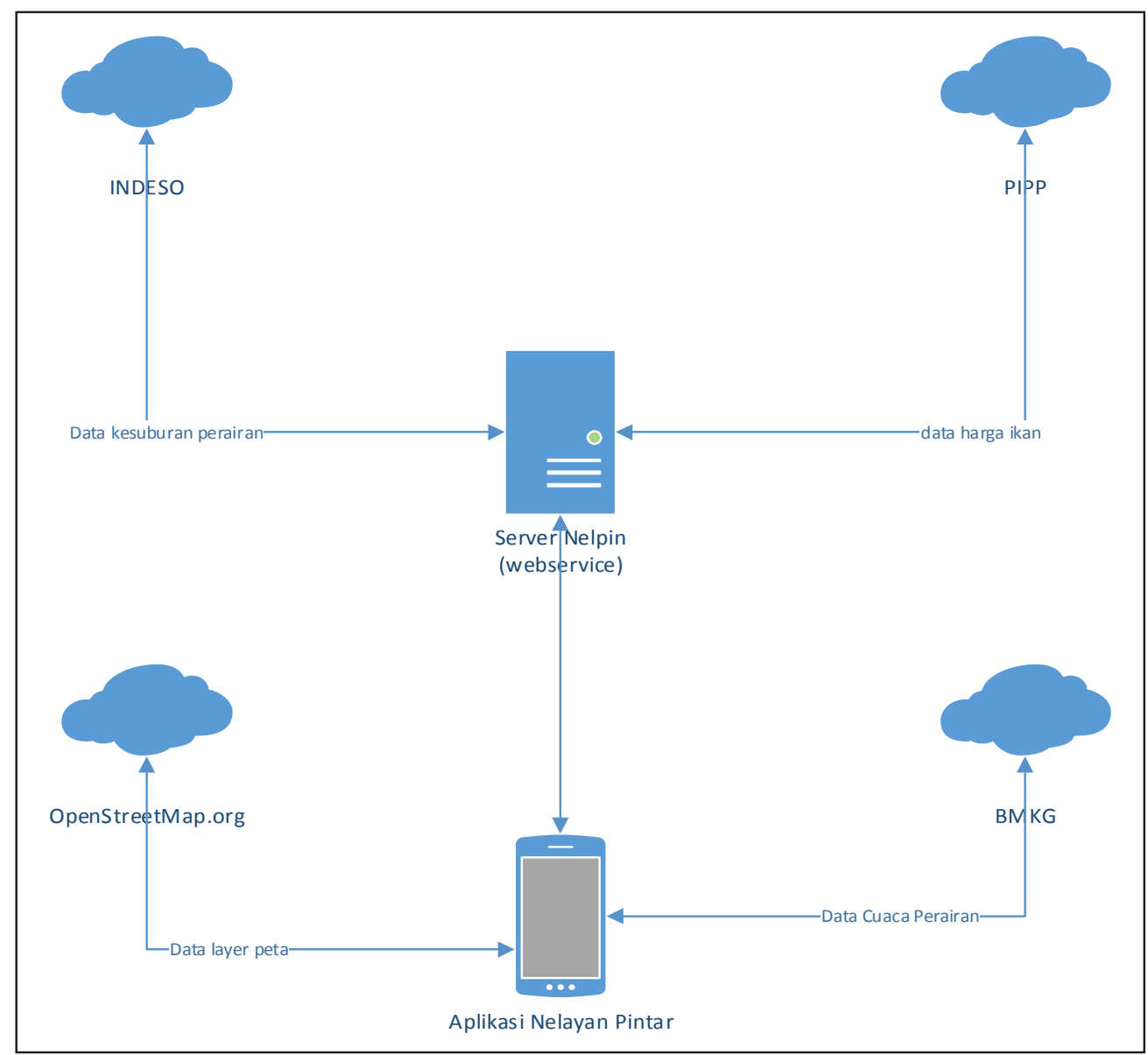

Gambar 1. Proses Integrasi Data ke Dalam Aplikasi Android Figure 1. Data Integrassion Process to Android Application

Sistem Informasi Nelayan Pintar merupakan suatu aplikasi berbasis android yang di dalamnya terdapat informasi terkini mengenai hal-hal yang dibutuhkan nelayan untuk melaut. Informasi ini meliputi data terkini daerah penangkapan ikan (DPI), kondisi cuaca, kesuburan perairan dan harga ikan (Pusat Pengkajian dan Perekayasaan Teknologi Kelautan dan Perikanan (P3TKP), 2015). Hal ini agar nelayan dapat langsung menuju ke lokasi penangkapan ikan, sehingga tidak perlu berburu mencari daerah penangkapan. Hal tersebut diharapkan mereka dapat menghemat biaya operasional kapal termasuk BBM. Selain itu, melalui informasi harga ikan terkini, nelayan dapat menjual ikannya dengan harga yang sesuai pasar. Dalam hal ini mengurangi resiko permainan harga oleh para tengkulak. Teknologi Sistem Informasi Nelayan Pintar diharapkan mampu meningkatkan serta mendongkrak hasil tangkapan para nelayan khususnya nelayan kecil. Dengan demikian, sistem informasi dapat membantu para nelayan untuk mengetahui beragam informasi terkait ikan dan digunakan sebagai pertimbangan (Paramita, 2016). Sumber data dan informasi yang digunakan dalam SINP bersumber dari lembaga atau instansi yang telah diakui sebagai penghasil data dan informasi yang telah teruji kebenarannya. Lembaga atau instansi tersebut seperti KKP dan Badan Meteorologi Klimatologi dan Geofisika (BMKG).

Sejak tahun 2000, Balai Penelitian dan Observasi Laut (BPOL) - KKP telah mengembangkan teknologi Peta Prakiraan Daerah Penangkapan Ikan (PPDPI). Pembuatan PPDPI didasarkan pada informasi sebaran konsentrasi klorofil-a, suhu permukaan laut dan anomali tinggi permukaan laut dari citra satelit MODIS. Terdapat 3 (tiga) jenis PPDI yang diproduksi oleh BPOL yaitu PPDPI Nasional, PPDPI Laut Sawu dan PPDPI Pelabuhan. Informasi PPDPI tersebut dapat diakses melalui website www.bpol.litbang. kkp.go.id/peta-pdpi, pelabuhan perikanan, Dinas Kelautan dan Perikanan setempat atau bisa melalui SMS center (Balai Penelitian dan Observasi Laut (BPOL), 2014). 


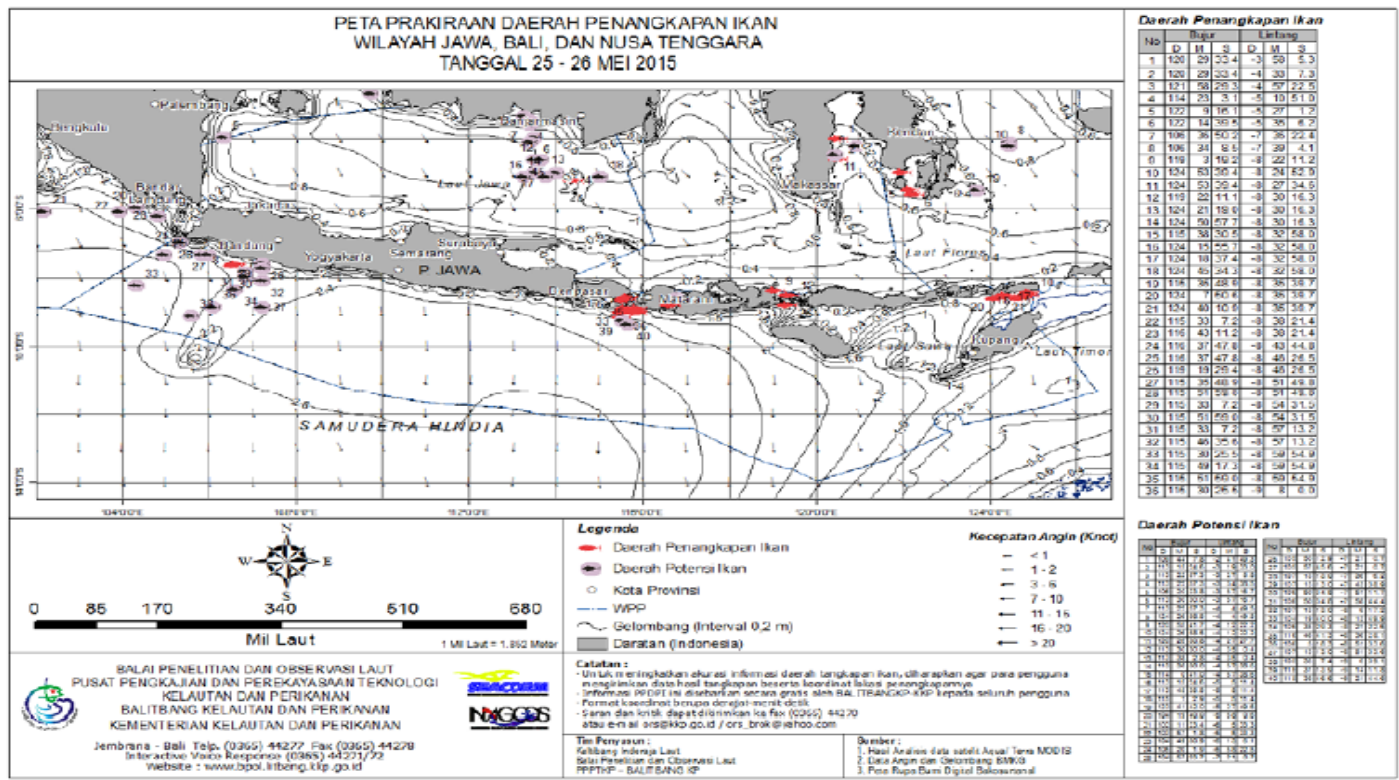

Gambar 2. Tampilan PPDPI (Sumber: www.bpol.litbang.kkp.go.id/peta-pdpi) Figure 2. PPDPI Display (Source: www.bpol.litbang.kkp.go.id/peta-pdpi)

Selain PPDPI, BPOL telah mengembangkan Peta Lokasi Penangkapan Ikan (PELIKAN) Tuna, PELIKAN Cakalang dan PELIKAN Lemuru. Informasi tersebut diintergrasikan dalam SINP agar dapat diakses langsung oleh para nelayan. Dengan demikian mereka dapat menghemat operasional sekaligus meningkatkan hasil tangkapan.

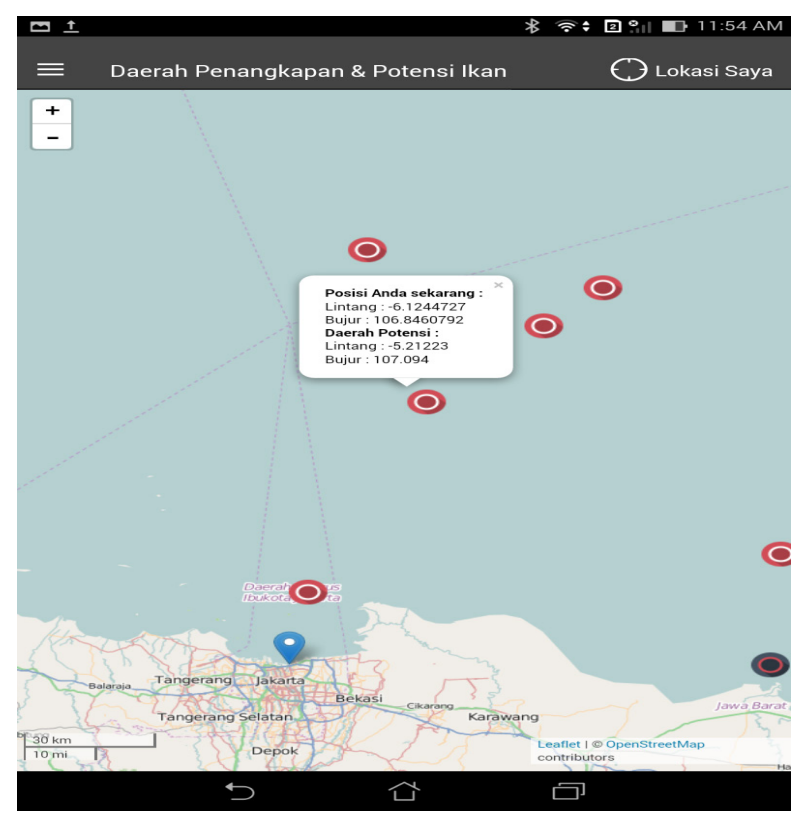

Gambar 3. Tampilan Informasi PPDPI di Aplikasi Android.

Figure 3. PPDPI Information Display in Android Application.

Informasi ini sangat dibutuhkan nelayan karena terkait dengan keselamatan saat berlayar atau operasi penangkapan ikan. Dengan mengetahui perkiraan cuaca, nelayan bisa mengetahui kapan waktu yang tepat untuk berlayar. Hal ini sangat berguna untuk menghindari badai dan gelombang tinggi di lautan. Berbekal informasi cuaca, nelayan dapat merencanakan rute yang aman dan menghindari perairan yang bercuaca buruk. Selain mempengaruhi faktor keselamatan, cuaca buruk dapat menyeabkan kerusakan pada mesin dan kapal ikan akibat terjebak badai.

Informasi prakiraan cuaca diperoleh dari BMKG. Konten dalam informasi meliputi informasi prakiraan cuaca rata-rata harian untuk pelayaran, prakiraan tinggi gelombang rata-rata, prakiraan cuaca pelabuhan dan prakiraan wilayah perairan. Selain itu BMKG juga membuat peta prakiraan tinggi gelombang, arus laut dan arah angin. Semua informasi tersebut ditampilkan di aplikasi android SINP agar mudah dibaca oleh nelayan.



Gambar 4. Tampilan Informasi Cuaca (Sumber: www. bmkg.go.id).

Figure 4. Weather Information Display(Source: www. bmkg.go.id). 


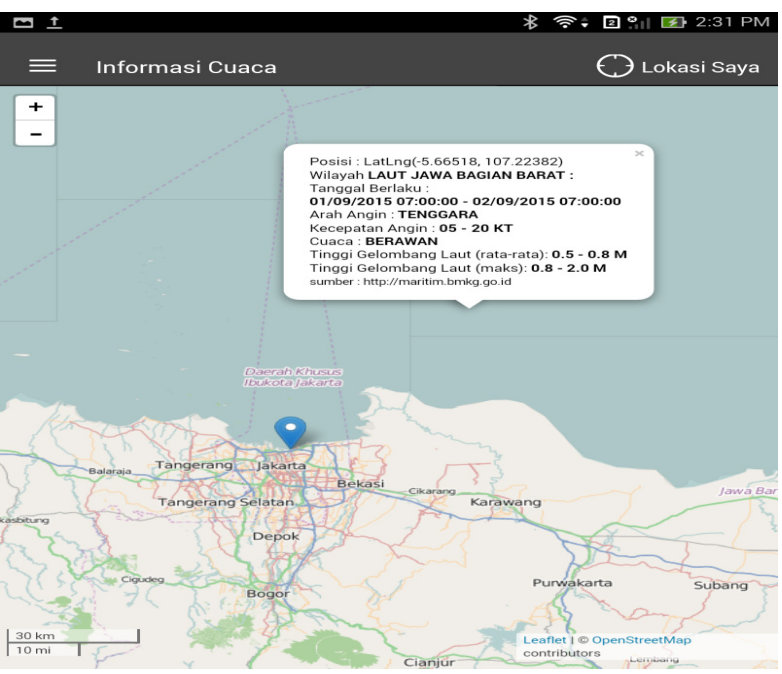

Gambar 5. Tampilan Informasi Cuaca di Aplikasi Android.

Figure 5. Weather Information Display in Android Application.

Penyediaan informasi harga ikan sangat diperlukan terkait dengan sistem tata niaga harga ikan. Pemerintah harus membuat sistem informasi harga ikan minimal di tingkat provinsi. Sebenarnya sistem harga ini minimal memuat 18 jenis ikan yang banyak diproduksi dan dikonsumsi seperti udang, teri, tongkol, tuna dan kembung. Sebenarnya tujuan utama sistem ini dibuat untuk menghindari kerugian nelayan akibat tengkulak (Wahyuni, 2014).

Saat ini informasi harga ikan sudah bisa diakses secara terbuka pelabuhan-pelabuhan maupun situs http://pipp.djpt.kkp.go.id/index.php/ produksidanharga. Di sana ditampilkan harga dan produksi ikan harian. Informasi ini diintegrasikan dengan SINP agar lebih mudah diakses oleh para nelayan. Harga ikan yang tertera berdasarkan nilai jual pedagang eceran yang berlaku setelah lelang di Tempat Pendaratan Ikan (TPI) (Direktorat Jenderal Perikanan Tangkap (DJPT), 2014).

Salah satu indikator kesuburan perairan adalah berlimpahnya zat hara yang merupakan zat penting untuk pembentukan produktifitas primer yaitu fitoplankton. Zat hara anorganik yang diperlukan fitoplankton untuk tumbuh dan berkembang biak adalah nitrogen dalam bentuk nitrat dan fosfor (Nybaken, 1992). Jadi fosfat dan nitrat merupakan zat hara yang penting bagi pertumbuhan dan metabolisme fitoplankton yang merupakan indikator untuk mengevaluasi kualitas dan tingkat kesuburan perairan (Ferianita et al., 2005).

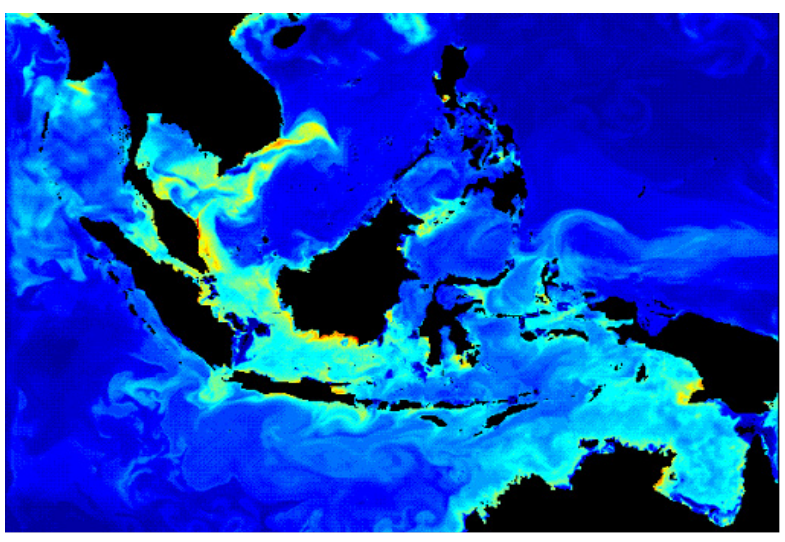

Gambar 7. Tampilan Informasi Kesuburan Perairan (Sumber: www. indeso.web.id).

Figure 7. Water Fertilities Display (Source: www. indeso.web.id).

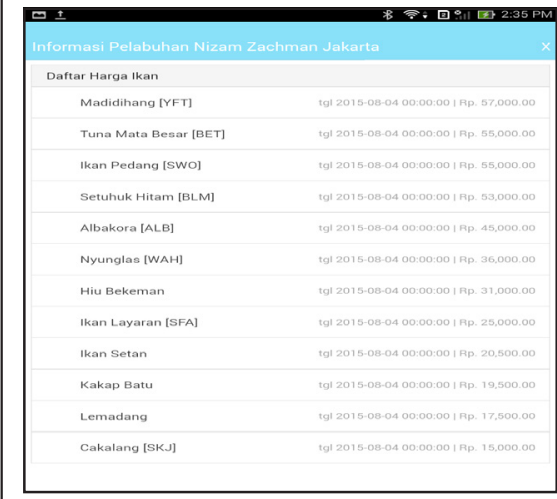

(a) Informasi harga ikan di suatu pelabuhan/ Fish pricing information at a port

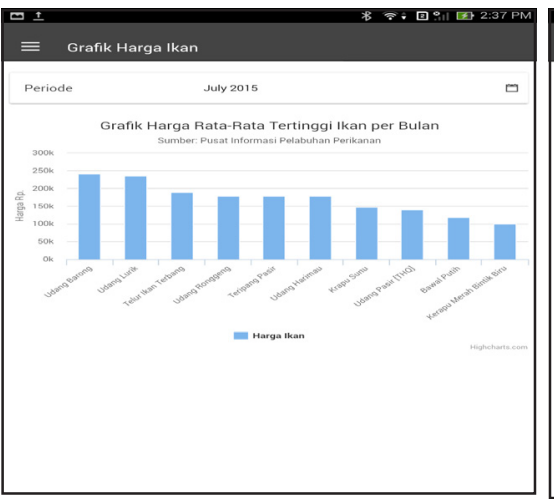

(b) Grafik harga rata-rata ikan per bulan secara nasional/ Graph of average monthly fish prices nationwide



(c) Grafik sebaran jenis ikan tertentu di berbagai pelabuhan perikanan/ Graph of distribution of certain types of fish in various fishing ports 


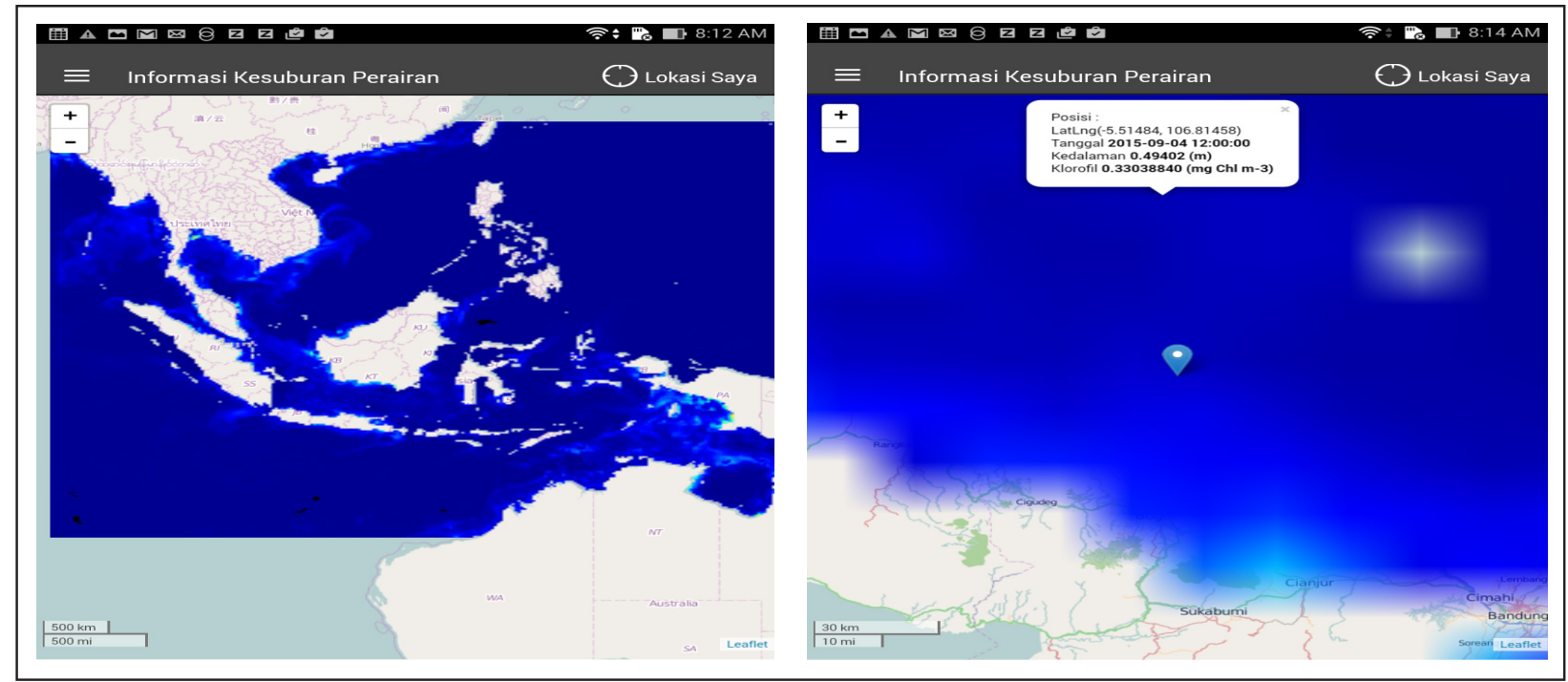

Gambar 8. Tampilan Informasi Kesuburan Perairan di Aplikasi Android

Figure 8. Water Fertilities Display in Android Application

\section{Karakteristik Responden SINP}

Usia responden sangat variatif yaitu dari umur 15 tahun sampai dengan umur 73 tahun. Menurut golongan umur, responden berumur 15-30 sebanyak $18 \%, 31-50$ tahun sebanyak $65 \%$ dan sisanya berumur pada kisaran 51-73 tahun. Para nelayan ini kebanyakan pada usia produktif.

Pendidikan nelayan responden cukup bagus dimana $40 \%$ sudah mengenyam pendidikan SMA. Sedangkan responden yang berpendidikan SD dan SMP sebanyak $26 \%$ masing-masing. Adapun yang berpendidikan tinggi yaitu setingkat sarjana atau D4 hanya $8 \%$. Detil data tingkat pendidikan responden dapat dilihat pada Tabel 2.
Ukuran kapal dari para nelayan sangat variatif mulai dari 2 GT sampai dengan 196 GT. Adapun distribusinya yaitu hampir sebagian adalah di bawah 10 GT dan dapat dikategorikan sebagai nelayan kecil menurut Undang-Undang Perlindungan Nelayan No 7 tahun 2016.

\section{Informasi Perkiraan Cuaca yang Dianggap Paling Berguna bagi Para Nelayan}

Sistem SINP membutuhkan perangkat lunak berbasis android sehingga lebih ditujukan untuk nelayan skala menengah ke atas. Hasil survei menunjukkan bahwa mayoritas para nelayan sering melihat prakiraan cuaca sebelum melaut yaitu mencapai $52 \%$ dari responden. Informasi

Tabel 2. Tingkat Pendidikan Responden.

Table 2. Education Level of Respondent.

\begin{tabular}{ccc}
\hline Pendidikan/ Education & Jumlah/ Total & Prosentase/ Percentage \\
\hline SD & 139 & 0.26 \\
SMP & 143 & 0.27 \\
SMA & 207 & 0.39 \\
S1 & 44 & 0.08 \\
S2 & 1 & 0.00 \\
\hline
\end{tabular}

Tabel 3. Ukuran Kapal Nelayan Responden.

Table 3. Fishing Boats Size of Respondent.

\begin{tabular}{cc}
\hline Ukuran Kapal (GT)/ Size & Persen/ Percent \\
\hline$<10$ & 40.88 \\
$10-30$ & 32.55 \\
$>30$ & 26.57 \\
\hline
\end{tabular}


cuaca yang paling bemanfaat bagi nelayan adalah gelombang dan badai. Gelombang $(48,61 \%)$ dan badai $(29,57 \%)$ sangat menentukan keputusan nelayan untuk melaut atau tidak sehingga sangat penting informasi tersebut ditampilkan dalam perangkat SINP dengan data yang akurat seperti ditampilkan pada Gambar 9. karena itu nelayan dapat menentukan kapan dan dimana suatu wilayah perairan yang sesuai atau cocok untuk melakukan penangkapan ikan. Pada musim-musim angin banyak sekali gejala-gejala yang ditimbulkannya. Pada wilayah perairan laut selatan sering terjadi gelombang yang besar ini dikarenakan pengaruh angin pada laut selatan

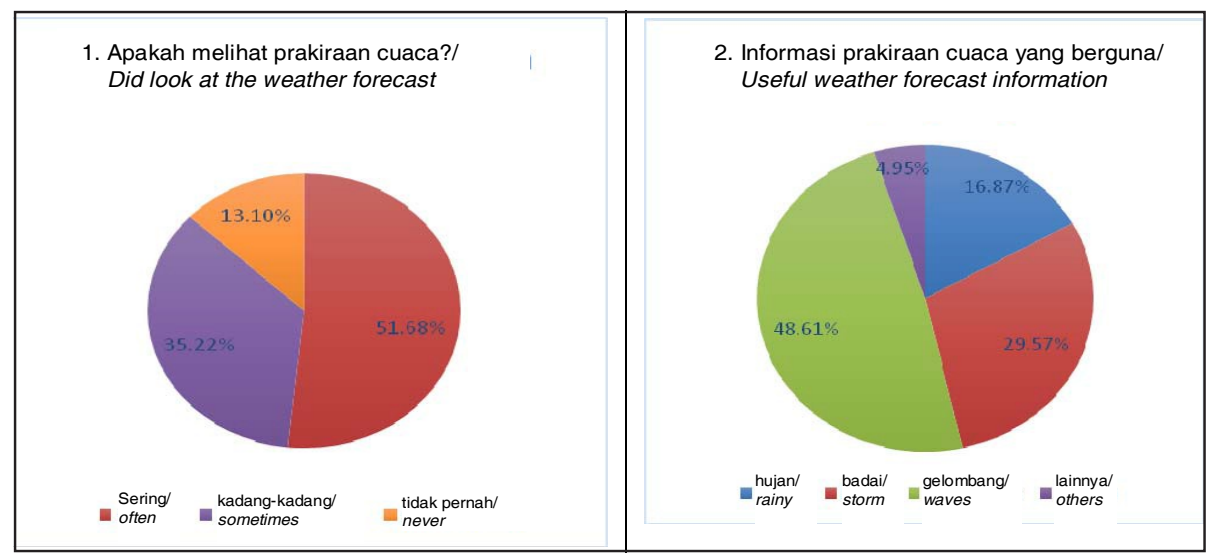

Gambar 9. Frekuensi Responden yang Melihat Prakiraan Cuaca Sebelum Melaut dan Informasi Cuaca yang Paling Berguna Menurut Responden.

Figure 9. Respondent Frequency who was Saw Forecast Before Fishing and Weather Information Which Useful According to Fisher's.

Gelombang pada permukaan air laut pada umumnya terjadi karena adanya tiupan angin di atas permukaan air laut yang bersangkutan, makin besar kecepatan atas kekuatan angin dan makin lama angin tersebut bertiup, maka makin besar atau makin tinggi gelombang yang ditimbulkannya. Meskipun gelombang di permukaan laut nampak berjalan ke suatu arah tertentu.

Keadaan gelombang suatu wilayah perairan akan menentukan keberadaan ikan, oleh lebih besar dibandingkan dengan Laut Jawa. Oleh sebab itu rancangan kapal dan alat tangkapnya pun berbeda, pada laut selatan kapal penangkapan perikanannya dirancang dengan pemecah gelombangnya lebih besar, ini dikarenakan pada wilayah laut selatan pengaruh anginnya lebih besar sehingga gelombangnya cukup tinggi. Oleh karena itu keberadaan gelombang pada suatu wilayah juga akan mempengaruhi bentuk kapal dan cara penangkapan ikan.

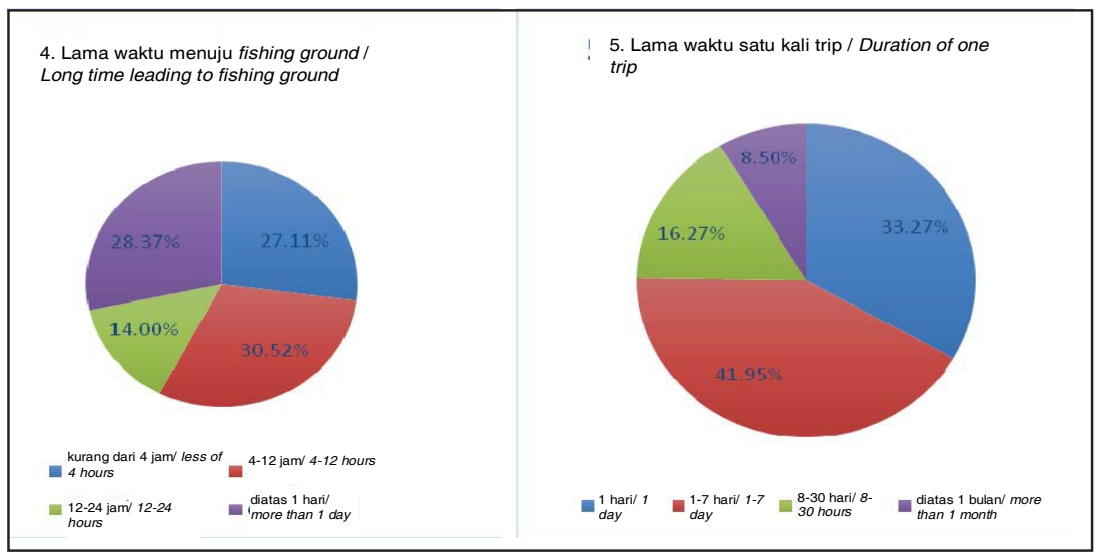

Gambar 10. Lama Waktu Menuju Fishing Ground (Daerah Penangkapan) dan Lama Waktu untuk Sekali Perjalanan Penangkapan Ikan.

Figure 10. Time Period to Fishing Ground and Time Period for Once Fishing Trip. 
Waktu yang dibutuhkan nelayan untuk menuju fishing ground sebagian besar tidak kurang dari 12 jam $(30,52 \%)$. Paling lama waktu yang dibutuhkan ke sana adalah 24 jam, itu pun hanya sedikit nelayan yang melakukannya (14\%). Lebih dari sebagian responden (60\%) menyatakan bahwa perjalanan ke fishing ground kurang dari 12 jam. Berdasarkan pengalaman menangkap ikan, pada umumnya para nelayan sudah tahu lokasi tempat penangkapan ikan dan tidak membutuhkan waktu lama untuk ke sana. Hal ini tidak serta merta berbanding lurus dengan lamanya melaut. Total lama melaut terdiri dari perjalanan menuju fishing ground, waktu untuk memancing ikan di satu atau lebih fishing ground dan perjalanan pulang. Total lama melaut lebih dipengaruhi oleh BBM, hasil tangkapan, kapasitas palkah, jumlah es yang dibawa dan perbekalan untuk seluruh ABK dan nakhoda kapal.

Data survei menunjukkan bawah kebanyakan nelayan membutuhkan waktu 1-7 hari $(41,95 \%)$ untuk kegiatan melautnya. Terdapat $33,27 \%$ responden yang menjawab butuh waktu sehari saja untuk melaut. Namun ada juga yang membutuhkan waktu melaut lebih lama yaitu 8-30 hari $(16,27 \%)$ dan di atas satu bulan $(8,5 \%)$. Lamanya waktu untuk melaut ini tergantung pada jenis ikan yang akan ditangkap dan jumlah BBM yang tersedia di kapal. Lamanya waktu melaut juga tergantung dengan target banyaknya ikan yang akan ditangkap. Kebutuhan BBM sangat tergantung dengan lamanya waktu yang untuk melaut. Semakin lama waktu untuk melaut, berbanding lurus dengan kebutuhan BBM.
Jumlah BBM yang dibutuhkan untuk melaut berkisar antara 100 hingga 1.000 liter. Dari data survei diperoleh bahwa $36,91 \%$ saja yang sering melihat daerah prakiraan penangkapan. Sisanya mereka kadang-kadang mengecek informasi tersebut $(45,45 \%)$ dan sisanya tidak pernah melihat $(17,64 \%)$ dapat dilihat pada Gambar 11).

Prediksi Daerah Penangkapan Ikan (fishing ground) merupakan informasi dan teknologi yang sangat bermanfaat bagi nelayan dan pengusaha yang bergerak pada bidang penangkapan ikan di laut. Informasi fishing ground merupakan kebutuhan vital yang diperlukan pada usaha penangkapan ikan berupa:

a. Titik koordinat pada posisi lintang dan bujur yang terdapat pada peta lokasi Daerah Penangkapan Ikan yang diberi tanda gambar ikan berwarna merah.

b. Titik koordinat pada posisi lintang dan bujur yang terdapat pada peta lokasi.

Potensi Daerah Penangkapan Ikan ditandai dengan gambar ikan berwarna ungu. Pada Potensi Daerah Penangkapan ini, ikan diperkirakan berada pada sekitar posisi lintang dan bujur yang ditetapkan. Dengan hasil menemukan titik koordinat lintang dan bujur lokasi penangkapan maupun potensi daerah penangkapan di laut nelayan dapat langsung mengoperasikan alat tangkap ikan yang dibawanya. Dengan memanfaatkan Peta DPI ini diharapkan para nelayan dapat menuju ke lokasi tangkapan secara lebih cepat dan efisien, yang berarti waktu melaut bisa berkurang sekaligus menghemat penggunaan BBM.

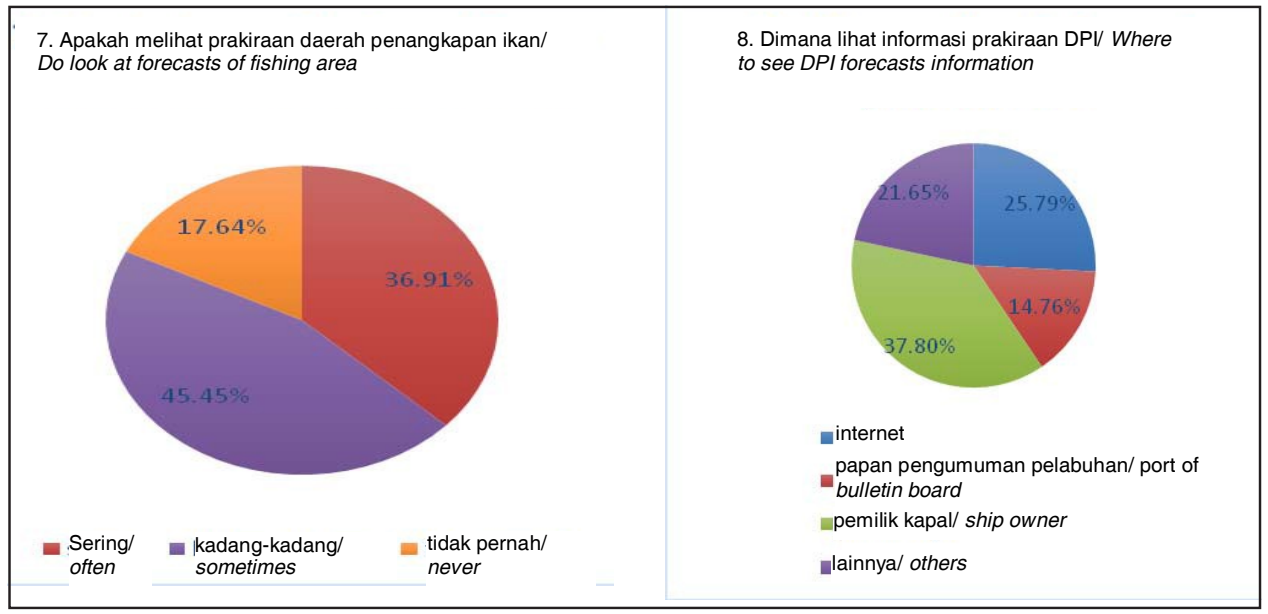

Gambar 11. Frekuensi Melihat Prakiraan Daerah Penangkapan Ikan (DPI) dan Sumber Media Mendapatkan Informasi DPI.

Figure 11. Frequency Viewed Regional Forecast Fishing (DPI) and the Media Source to Get Information DPI. 


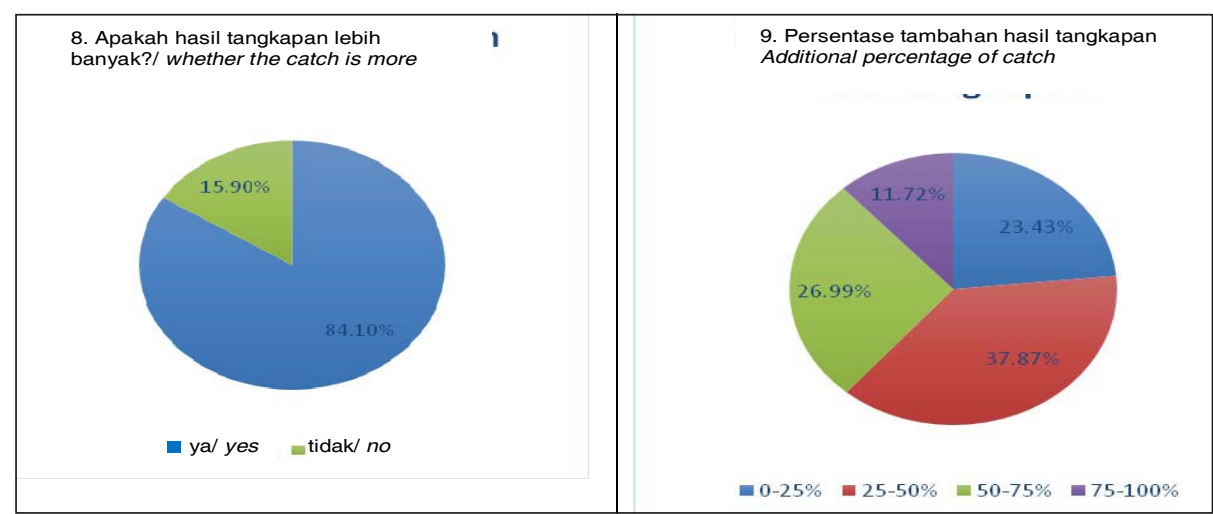

\section{Gambar 12. Persepsi Nelayan Tentang Manfaat DPI Terhadap Hasil Tangkapan dan Prosentase Penambahan Hasil Tangkapan Dengan Membawa Informasi DPI.}

Figure 12. Perception of Fisher on Benefits of DPI Toward Catch and Percentation of Catch Added With Bringing DPI Information.

Kapten pada umumnya menggunakan beberapa media untuk mendapatkan informasi daerah penangkapan ikan, yaitu dari juragan atau pemilik kapal $(37,8 \%)$, sisanya informasi ini diperoleh dari internet, papan pengumuman yang adadipelabuhan dan medialainnya. Ini berarti terjadi tukar menukar informasi yang cukup kuat antara pemilik kapal dan nakhoda yang dipercayainya. Pemilik kapal mungkin juga merupakan nakhoda atau dulu pernah menjadi nakhoda kapal lain sebelum membangun kapalnya sendiri.

\section{Persepsi Nelayan Terhadap NISP}

Nelayan menyatakan bahwa hasil tangkapannya lebih banyak ketika melihat peta prakiraan penangkapan sebelum melaut. Untuk para nelayan yang melihat peta $\mathrm{DPI}$, hasil tangkapan mereka terbukti lebih banyak $(84,10 \%)$. Hanya $15,90 \%$ saja yang menjawab bahwa petunjuk yang ada pada peta DPI tidak mempengaruhi hasil tangkapan. Pertambahan jumlah ikan yang ditangkap bervariasi, paling sedikit adalah $11,72 \%$ dan paling banyak adalah $37,87 \%$. Hal ini berarti informasi yang diperoleh nelayan dari peta DPI sangat membantu dalam meningkatkan hasil tangkapan mereka.

\section{Informasi Harga Ikan}

Di negara-negara maju, nelayan cenderung melihat harga ikan sebelum melaut atau sudah mempunyai kontrak dengan pembeli tentang harga ikan yang akan ditangkap. Akan tetapi, tidak demikian di Indonesia. Salah satu alasan yang mungkin adalah bahwa harga lebih banyak didominasi oleh para tengkulak di pelabuhanpelabuhan perikanan untuk nelayan skala kecil.
Sistem informasi harga ikan ini sangat penting dalam sistem tata niaga ikan sebagai acuan dan harus ada minimal di tingkat propinsi. Sistem informasi harga ikan itu minimal memuat harga 18 jenis ikan yang banyak diproduksi dan dikonsumsi di Indonesia seperti udang, teri, tongkol, tuna dan kembung.

Namun, meskipun begitu belum semua nelayan menyadari tentang pentingnya mengupdate harga ikan. Dari hasil kuisoner, hanya sebagian saja yang selalu melihat informasi harga ikan (38,35\%). Sebanyak 35,60\% yang hanya kadang-kadang saja melihatnya, bahkan sebanyak $26,06 \%$ tidak pernah melihat informasi harga ikan. Untuk melihat informasi harga ikan, para nelayan paling banyak mendapatkan dari pemilik kapal (55,02\%). Sebanyak 16,47\% dari internet dan 9,24\% dari papan pengumuman pelabuhan. Sisanya $(19,28 \%)$ dari sumber lain-lain. Kebanyakan dari mereka melihat informasi ini setelah pulang melaut $(62,90 \%)$ dan sebanyak $33,53 \%$ melihatnya sebelum berangkat melaut.

\section{Manfaat dan Tingkat Kesulitan Aplikasi}

Dari hasil pengenalan dan sosialisasi aplikasi Sistem Informasi Nelayan Pintar (SINP) kepada para nelayan tangkap, pemilik kapal dan pihak pelabuhan, sebagian besar dari mereka menyatakan bahwa aplikasi SINP cukup bermanfaat untuk mendukung usaha penangkapan ikan di laut. Hanya sebagian kecil saja $(1,69 \%)$ yang menyatakan tidak bermanfaat dan sisanya $(11,42 \%)$ menyatakan tidak tahu. Para pelaku usaha di bidang penangkapan ikan ini berharap bahwa dengan adanya aplikasi SINP bisa mendukung peningkatan hasil usaha penangkapan ikan. 


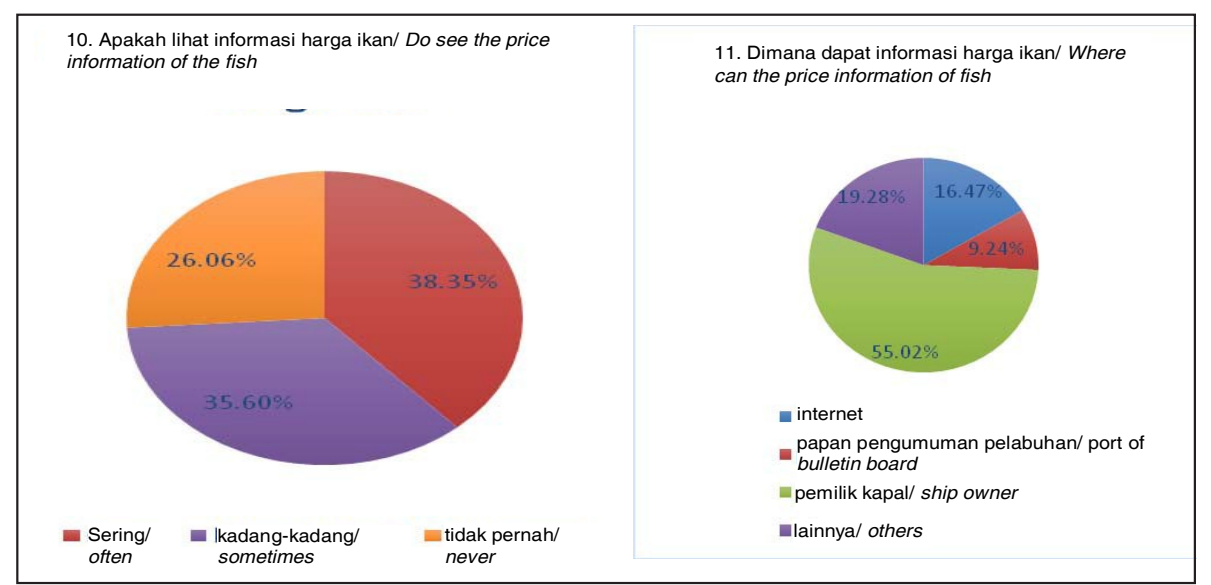

Gambar 13. Frekuensi Nelayan yang Melihat Informasi Harga Ikan Sebelum Melaut (Kiri) dan Media Mendapatkan Informasi Tentang Harga Ikan (Kanan).

Figure 13. Frequency of Fisher Viewed Fish Price Information Before Fishing (Left) and the Media to Get Information About Fish Prices (Right).

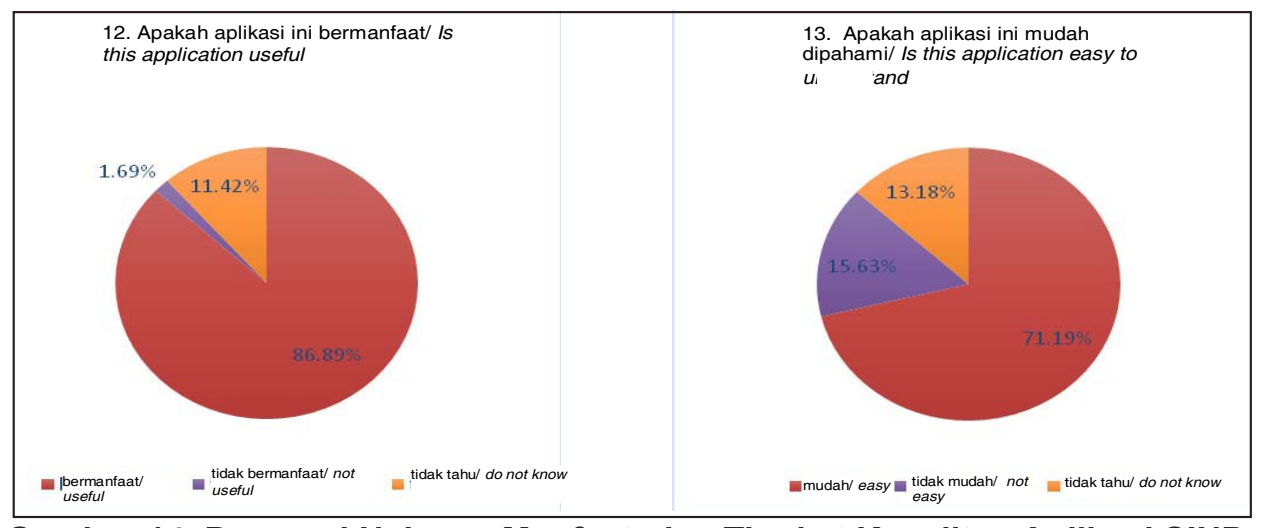

Gambar 14. Persepsi Nelayan Manfaat dan Tingkat Kesulitan Aplikasi SINP Figure 14. Fisher Perception for Benefits and Difficulty SINP Application

Aplikasi SINP dibuat sesederhana mungkin namun tetap dengan data dan informasi yang cukup lengkap agar mudah dipahami oleh para pengguna. Hal initerbuktibahwahampir sebagian besar peserta sosialisasi dapat mengerti dan menggunakan aplikasi SINP secara mudah $(71,19 \%)$. Sebanyak $15,63 \%$ menjawab tidak mudah dan $13,18 \%$ tidak tahu. Hal ini kemungkinan disebabkan karena mereka tidak menggunakan smartphone berbasis android, padahal aplikasi SINP adalah aplikasi yang berbasis sistem android.

\section{Informasi Aplikasi yang Sangat Berguna}

Menurut para pengguna, dari keseluruhan konten aplikasi SINP, informasi mengenai daerah penangkapan ikan dianggap yang paling penting $(42,08 \%)$. Namun banyak juga yang menyatakan bahwa informasi cuaca juga penting (35,09\%). Lainnya mengaggap kesuburan perairan dan informasi harga ikan cukup penting. Keempat jenis informasi ini diangap para pengguna sangat penting untuk mendukung usaha penangkapan ikan di laut.

Sebaliknya, informasi yang dianggap paling tidak bermanfaat adalah harga ikan $(40,11 \%)$, menyusul kesuburan perairan $(38,16 \%)$, daerah penangkapan ikan $(11,14 \%)$ dan informasi cuaca $(10,48 \%)$. Jika dicermati, hal ini cukup menarik mengapa informasi harga ikan dan daerah penangkapan ikan dianggap tidak cukup penting untuk para pelaku usaha penangkapan ikan. Hal ini mungkin disebabkan karena informasi harga ikan yang terdapat pada aplikasi kurang up to date terhadap situasi harga pasar terkini sehingga nelayan merasa tidak perlu mengikutinya. Acuan harga ikan yang mereka gunakan adalah harga ikan di pasaran saat itu. Sedangkan untuk daerah penangkapan ikan, biasanya para nelayan sebelum melaut sudah punya lokasi yang biasa mereka tuju dan selalu mendapatkan tangkapan ikan tanpa harus berpatokan pada informasi 


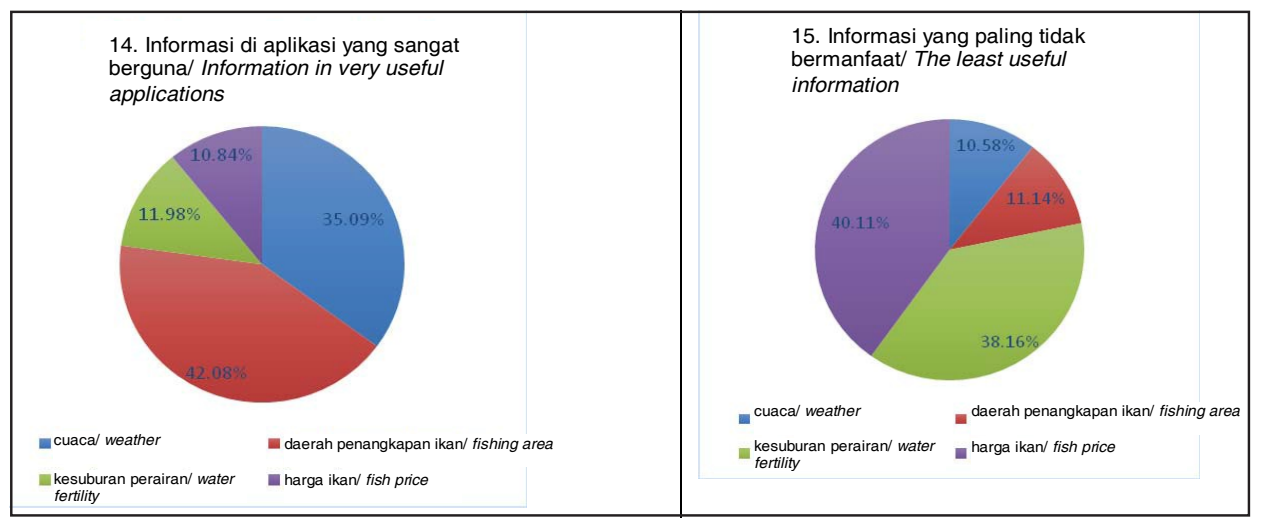

Gambar 15. Persepsi Nelayan Tentang Informasi yang Paling Bermanfaat dan Kurang Bermanfaat Figure 15. Fisher Perception about The Most Helpful information and Less Helpful

daerah penangkapan ikan. Atau juga kemungkinan lainnya, nelayan sudah menggunakan acuan dari peta DPI namun ternyata setelah kesana malah tidak mendapatkan ikan.

Persepsi responden menyatakan bahwa tingkat informasi kesuburan perairan dianggap informasi yang kurang bermanfaat berlawanan dengan jawaban pertanyaan sebelumnya bahwa Daerah Penangkapan Ikan adalah informasi paling bermanfaat. Hal ini sangat dimungkinkan ketidak mengertian korelasi dari tingkat kesuburan perairan dengan Daerah Penangkapan Ikan. Tingkat kesuburan perairan biasanya berkorelasi langsung dengan Daerah Penangkapan Ikan.

\section{KESIMPULAN DAN IMPLIKASI KEBIJAKAN}

\section{Kesimpulan}

SINP merupakan sistem operasi yang mudah difahami dan dioperasikan oleh pengguna yaitu kapten kapal. Informasi Daerah Penangkapan Ikan adalah informasi paling penting yang diperlukan para nelayan sebelum melaut dan disusul oleh informasi prakiraan cuaca. Informasi cuaca sangat penting untuk keselamatan para nelayan. Informasi DPI adalah penting untuk menemukan daerah fishing ground secara cepat sehingga menghemat bahan bakar minyak dan meningkatkan hasil tangkapan dan produktifis kapal tersebut.

Para responden menyatakan informasi yang dirasa sangat bermanfaat adalah peta DPI dan prakiraan cuaca sebelum melaut. Prakiraan cuaca ini penting untuk keselamatan nelayan. Dalam pertanyaan lanjutan tentang manfaat informasi Dearah Penangkapan Ikan ini, responden $84.1 \%$ menyatakan bawah informasi atau peta DPI meningkatkan hasil tangkapan dibanding tidak membaca peta DPI. Peta DPI dapat diperoleh di setiap pelabuhan perikanan seluruh Indonesia. Para nelayan juga merasa bahwa sistem SINP cukup mudah untuk dioperasikan.

\section{Implikasi Kebijakan}

Keakuratan DPI menjadi komponen penting dalam pengembangan SINP mendatang, Pengembangan SINP dapat ditunjang oleh hasil kajian estimasi abundance stock ikan (kelimpahan stok ikan) berdasarkan pemodelan dinamik INDESO yang dikembangkan oleh Pusat Penelitian Sumber Daya Laut dan Pesisir.

\section{UCAPAN TERIMA KASIH}

Penulis mengucapkan terima kasih kepada semua responden dalam survey NELPIN ini dan kepada para pimpinan di Pelabuhan Perikanan seluruh Indonesia yang memungkinkan kajian ini terlaksana. Penulis juga mengucapkan terima kasih kepada Pusat Penelitian dan Pengembangan Teknologi Keluatan (P3TKP), Balitbang KP atas dukungan pendanaan kegiatan NELPIN tahun 2015.

\section{DAFTAR PUSTAKA}

Balai Penelitian dan Observasi Laut (BPOL). 2014. Panduan Membaca Peta Prakiraan Daerah Penangkapan Ikan. http://www.bpol.litbang.kkp. go.id/file/ppdpi/PANDUAN_PETA_SECARA_ UMUM.pdf.

Direktorat Jendral perikanan Tangkap (DJPT). 2014. Pusat Informasi Pelabuhan Perikanan. Jakarta.

Ferianita, M., H. Haeruman dan L. C. Sitepu. 2005. Komunitas Fitoplankton sebagai Bioindikator Kualitas Perairan Teluk Jakarta. Seminar Nasional 
MIPA 2005. FMIPA Universitas Indonesia, 24-26 November 2005. Jakarta.

Muawanah, U. dan S. Hidayat. 2016. The impact of Coral Reef Management Project (COREMAP) on peoples' livelihood in Indonesia, working paper, 20 pages.

McClanahan, T. R., J. Maina and J. Davies. 2005. Perceptions of resource users and managers towards fisheries management options in Kenyan coral reefs. Fisheries Management and Ecology, 12(2), pp.105-112.

Muawanah, U., R. S. Pomeroy and C. Marlessy. 2012. Revisiting fish wars: conflict and collaboration over fisheries in Indonesia. Coastal Management, 40(3), pp.279-288.

Nybaken, J. W. 1992. Biologi Laut, Suatu Pendekatan Ekologis, diterjemahkan oleh M.Erdman Kesbiono, D.G Bagen, M. Hutomo dan S. Sukristyono, Gramedia, Jakarta.

Pérez-Sánchez, E. and J. F. Muir. 2003. Fishermen perception on resources management and aquaculture development in the Mecoacan estuary, Tabasco, Mexico. Ocean \& coastal management, 46(6), pp.681-700.

Pet-Soede, C., M. A. M. Machiels, M. A. Stam and W. L. T. Van Densen. 1999. Trends in an Indonesian coastal fishery based on catch and effort statistics and implications for the perception of the state of the stocks by fisheries officials. Fisheries Research, 42(1), pp.41-56.

Pomeroy, R. and F. Douvere. 2008. The engagement of stakeholders in the marine spatial planning process. Marine Policy, 32(5), pp.816-822.

Pomeroy, R., J. Parks, R. Pollnac, T. Campson, E. Genio, C. Marlessy, E. Holle, M. Pido, A. Nissapa, S. Boromthanarat and N. T. Hue. 2007. Fish wars: Conflict and collaboration in fisheries management in Southeast Asia. Marine Policy, 31(6), pp.645-656.

Pusat Pengkajian dan Perekayasaan Teknologi Kelautan dan Perikanan (P3TKP), 2015, Buku Petunjuk Penggunaan Sistem Informasi Nelayan Pintar, Balitbang KP-KKP, Jakarta.

Wahyuni, S. 2014. Pentingnya Sistem Informasi Harga Ikan, Surya Pos, Surabaya 29 Mei 2014.http:// surabaya.tribunnews.com/2014/05/29/pentingnya-sistem-informasi-harga-ikan, diakses tanggal 10 Agustus 2015.
Zamroni, A. and M. Yamao. 2011. Coastal resource management: fishermen's perceptions of seaweed farming in Indonesia. World Academy of Science, Engineering and Technology, 60, pp.32-38. 